\title{
Selective ACTH Insensitivity, Achalasia, and Alacrima: a Multisystem Disorder Presenting in Childhood
}

\author{
MITCHELL E. GEFFNER, ${ }^{(39)}$ BARBARA M. LIPPE, SOLOMON A. KAPLAN, \\ WILLIAM E. BERQUIST, J. BRONWYN BATEMAN, VICTORIA I. PATERNO, AND \\ ROBERT SEEGAN \\ Divisions of Pediatric Endocrinology [M.E.G., B.M.L., S.A.K.], Pediatric Gastroenterology [W.E.B.], and the \\ Department of Pediatrics [V.I.P.], UCLA Hospital and Clinics, and the Jules Stein Eye Institute [J.B.B.], UCLA \\ School of Medicine, Los Angeles, California, and Endocrine Sciences [R.S.], Tarzana, California, USA
}

\begin{abstract}
Summary
A 31/2-year-old male is described with the rare triad of ACTH insensitivity, achalasia, and alacrima. Adrenal insufficiency presented with hypoglycemia and hyperpigmentation at age $2 \frac{1}{2}$ years. Achalasia was diagnosed at age $3 \frac{1}{2}$ years and alacrima, retrospectively, had been present since birth.

Evaluation of adrenal function revealed complete resistance of the glucocorticoid-producing zonas fasciculata and reticularis to both endogenous and exogenous ACTH. No chemical evidence was found for the presence of either an abnormal ACTH molecule or a circulating antibody to ACTH. Additionally, adrenal mineralocorticoid function was clearly responsive to both exogenous ACTH and to perturbations of the renin-angiotensin system. Only glucocorticoid deficiency due to selective ACTH resistance was documented.

Shortly after diagnosis, glucocorticoid production could be stimulated by intravenous theophylline administration. Presumably, this agent, whose intracellular actions may be mediated by either enhancement of cyclic AMP action or alterations in calcium transport, circumvented the usual interaction of ACTH with its receptor and thereby stimulated steroidogenesis. The responsiveness to theophylline was lost 1 year later, perhaps as a result of final atrophy of the zonas fasciculata and reticularis secondary to lack of effective ACTH stimulation; thus, our patient appears to have a unique syndrome characterized by ACTH insensitivity and a multifocal defect of the autonomic, specifically parasympathetic, nervous system, resulting in achalasia and alacrima. A putative pathogenic defect linking hormone-receptor cyclic AMP-mediated processes with abnormalities in parasympathetic neuronal innervation or receptor-mediated transmitter function, as may occur in achalasia and alacrima, remains to be demonstrated.
\end{abstract}

\section{Abbreviations}

LES, lower esophageal sphincter

renin-SRC, serum renin concentration

RIA, radioimmunoassay

ZFZR, zonas fasciculata and reticularis

ZG, zona glomerulosa

\section{INTRODUCTION}

The association of ACTH insensitivity with achalasia and alacrima constitutes a rare multisystem disorder $(1,20)$. We report studies on a male patient with this triad in whom we show that the adrenal ACTH resistance is selective, affecting the ZFZR while sparing the ZG; however, early in this child's life, the selective unresponsiveness of these zones could be circumvented, and cortisol secretion stimulated, through the use of a theophylline infusion. An abnormality of receptor-transmitter function involving the cyclic-AMP system appears to be a component of the adrenal defect in this syndrome. Although a transmitter defect in the parasympathetic nervous system could be responsible for development of the achalasia and alacrima, the nature of the neurologic abnormality and its relationship to the adrenal lesion remains unclear.

\section{CASE REPORT}

E.M., a 21/2-year-old Mexican-American male, presented initially at age 2 years with two convulsions, each associated with a period of prolonged fasting and one with documented hypoglycemia (plasma glucose, $28 \mathrm{mg} / \mathrm{dl}$ ). Hyperpigmentation of the skin was noted which had, retrospectively, been evolving for 1 year. Additionally, the patient had chronic redness of the eyes. There was no family history of hyperpigmentation or hypoglycemia. He was first-born and his non-consanguineous parents have subsequently had two other male children.

On physical examination, he was $88 \mathrm{~cm}$ in height $(25$ th percentile) and weighed $11.25 \mathrm{~kg}$ (5th percentile). He had no dysmorphic features, had normal external genitalia, and had no organomegaly. Fungiform papillae were seen on his tongue. Generalized hyperpigmentation was noted, most prominently on the lips, tongue, pressure points, and areas of skin trauma. The remainder of the examination was unremarkable.

Initial laboratory determinations at 8:00 AM after an overnight fast showed a plasma glucose of $10 \mathrm{mg} / \mathrm{dl}$ and serum insulin of 4 $\mu \mathrm{U} / \mathrm{ml}$. Serum cortisol was undetectable whereas plasma ACTH was $>2000 \mathrm{pg} / \mathrm{ml}$ (normal, $20-100 \mathrm{pg} / \mathrm{ml}$ ). Serum sodium was 137 $\mathrm{mEq} /$ liter and potassium $4.8 \mathrm{mEq} /$ liter. Circulating anti-adrenal antibodies were undetectable (26).

Adrenocortical reserve was tested by intravenous administration of $0.25 \mathrm{mg} \mathrm{ACTH}$ (Cortrosyn, synthetic $\alpha 1,24$-adrenocorticotrophin). Thirty minutes thereafter the serum cortisol concentration remained undetectable. Because salt loss was not apparent, a diagnosis of adrenal glucocorticoid insufficiency was made and replacement therapy with hydrocortisone alone was instituted (12 $\mathrm{mg} \cdot \mathrm{m}^{2} \cdot$ day $^{-1}$ in divided doses).

One year later, weight gain was noted to be poor and spontaneous vomiting of undigested food with general preference for soft solids and liquids was noted.

\section{MATERIALS AND METHODS}

Serum cortisol determinations were performed with the Autopak ${ }^{125}$ Cortisol Test System (Micromedic System, Horsham, PA). Even large concentrations of theophylline do not interfere with the RIA of cortisol (as performed in our laboratories). Serum aldosterone was measured with the $\mathrm{I}^{125}$ Aldosterone Assay Kit 
(Diagnostic Products Corporation, Los Angeles, CA). Renin-SRC was measured by a technique involving the addition of exogenous hog renin substrate according to the method of Gould et al. (13). Plasma ACTH concentrations were measured following Quso extraction in a system adapted from Berson and Yalow (5). In addition, plasma ACTH was measured in serial dilutions of the patient's plasma in which the initial ACTH concentration was $>2000 \mathrm{pg} / \mathrm{ml}$. HLA-typing was performed at the UCLA Tissue Typing Laboratory.

Endoscopy and esophageal biopsies were performed by one of us (WEB) using standard pediatric techniques (2). Esophageal manometry, using a continuously perfused system, was also performed (8). LES pressure measurement was calculated on mean mid-respiratory pressure in $\mathrm{mmHg}$ with intragastric pressure as baseline. Conjunctival and funduscopic examinations were also performed by one of us (JBB). Intradermal histamine phosphate $(1: 1000)$ was administered $(0.1 \mathrm{ml})(3)$.

The studies described below were performed with the approval of the UCLA Human Subject Protection Committee; informed consent was obtained from the patient's parents.

\section{RESULTS}

Forty-eight hours before each hormonal testing period the patient's corticosteroid medication was changed from hydrocortisone to either dexamethasone or prednisone, neither of which interferes with the RIA for endogenously produced cortisol.

To assess $\mathrm{ZG}$ responsiveness to exogenous $\mathrm{ACTH}$, high-dose dexamethasone pretreatment $\left(0.16 \mathrm{mg} \cdot \mathrm{kg}^{-1} \cdot \mathrm{day}^{-1}\right.$ for $\left.48 \mathrm{~h}\right)$ was used to suppress endogenous ACTH. This was followed by administration of Cortrosyn at 8:00 AM following a 60-min period during which the patient was kept supine. The 8:00 AM plasma ACTH concentration was suppressed to $130 \mathrm{pg} / \mathrm{ml}$. Thirty minutes after injection, the serum aldosterone concentration rose from 9.0 to $23.7 \mathrm{ng} / \mathrm{dl}$ whereas renin-SRC did not increase appreciably (Fig. 1). Cortisol remained undetectable. After intravenous Cortrosyn, the normal mean increment in aldosterone above baseline is $14 \mathrm{ng} / \mathrm{dl}$ (range $4-29 \mathrm{ng} / \mathrm{dl}$ ) and cortisol is $16 \mu \mathrm{g} / \mathrm{dl}$ (range, $7-$ $40 \mu \mathrm{g} / \mathrm{dl})(7)$.

Responsiveness of the $\mathrm{ZG}$ to the renin-angiotensin system was evaluated by bolus intravenous injection of furosemide $(1 \mathrm{mg} / \mathrm{kg}$ ) to evoke diuresis and maintenance of upright posture for $60 \mathrm{~min}$ thereafter. The results are summarized in Figure 2.

Finally, an intravenous theophylline stimulation test was performed to determine if adrenocortical glucocorticoids could be stimulated by another mechanism that would presumably increase the intracellular availability of cyclic AMP and/or calcium. A protocol was adapted from the doses of theophylline used to treat patients with asthma (27), in which a loading dose of $5 \mathrm{mg} / \mathrm{kg}$ is administered over $20 \mathrm{~min}$ followed by a dose of $1.0 \mathrm{mg} \cdot \mathrm{kg}^{-1} \cdot \mathrm{h}^{-1}$ for $2 \mathrm{~h}$. The basal ACTH concentration was suppressed to 260 $\mathrm{pg} / \mathrm{ml}$ and serum cortisol was undetectable before theophylline infusion; however, $2 \mathrm{~h}$ after beginning the infusion of theophylline,

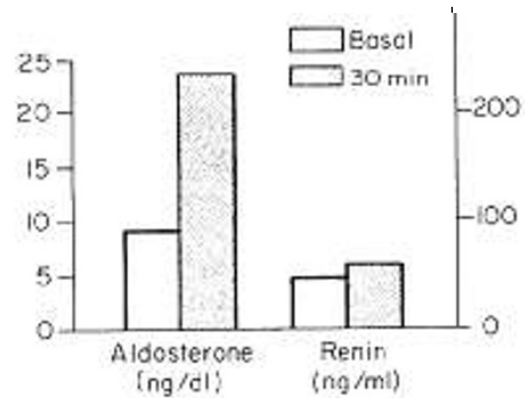

Fig. 1. Responsiveness of the zona glomerulosa to cortrosyn (ACTH). Aldosterone (left-hand bars) responses before and after $0.25 \mathrm{mg}$ of intravenous Cortrosyn are shown. Elimination of postural effects is shown by the lack of concomitant significant serum renin concentration rise (right-hand bars).

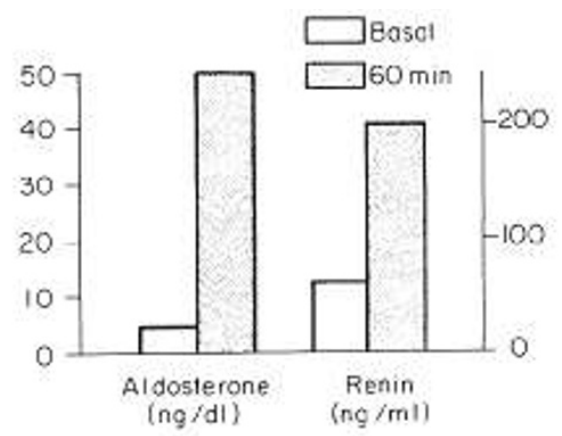

Fig. 2. Responsiveness of the zona glomerulosa to stimulation by the renin-angiotensin system. Aldosterone (left-hand bars) and serum renin concentration (right-hand bars) responses before and after $1 \mathrm{mg} / \mathrm{kg}$ of intravenous furosemide (resulting in an $8 \mathrm{ml} / \mathrm{h}$ diuresis) and $1 \mathrm{~h}$ of upright posture are shown. The resultant salt-water depletion physiologically activates the renin-angiotensin system and, secondarily, aldosterone release by the zona glomerulosa.

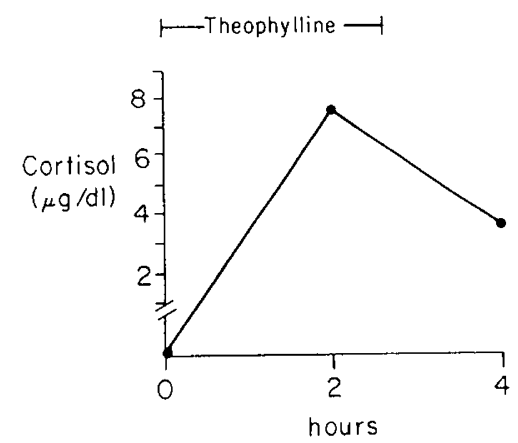

Fig. 3. Effect of theophylline on cortisol production. Intravenous theophylline was administered at age $2 \frac{1}{2}$ years as a loading dose of $5 \mathrm{mg} / \mathrm{kg}$ followed by an infusion of $1.0 \mathrm{mg} / \mathrm{kg} / \mathrm{h}$ for $2 \mathrm{~h}$. Two hours after the theophylline infusion was initiated, serum cortisol was detectable for the first time at a concentration of $7.5 \mu \mathrm{g} / \mathrm{dl}$, and was still detectable at a concentration of $3.5 \mu \mathrm{g} / \mathrm{dl} 2 \mathrm{~h}$ after the infusion was terminated.

cortisol, at a concentration of $7.5 \mu \mathrm{g} / \mathrm{dl}$, was detected in the serum for the first time. The serum theophylline concentration at this time was $16 \mu \mathrm{g} / \mathrm{ml}$. Two hours after the theophylline infusion was terminated, serum cortisol was still detectable at a concentration of $2.5 \mu \mathrm{g} / \mathrm{dl}$ (Fig. 3).

One year later, ACTH, furosemide, and theophylline stimulation tests were again performed according to the above protocols. With the plasma ACTH concentration suppressed to $83 \mathrm{pg} / \mathrm{ml}$, cortisol remained undetectable in all samples of blood obtained. Aldosterone (Table 1) and renin-SRC concentrations were again found to be normal.

Serial dilutions of a sample of the patient's plasma containing ACTH $>2000 \mathrm{pg} / \mathrm{ml}$ were assayed for ACTH. These dilutions resulted in curves parallel to those of dilutions of standards making it unlikely that the increased concentration of ACTH was due to interference by a factor present in the plasma.

In evaluation of the patient's gastrointestinal problems, contrast medium radiologic studies of the upper gastrointestinal tract and videoesophagram demonstrated disordered esophageal motility characterized by prominent tertiary waves, a dilated esophageal body, a "beak-like" configuration of a persistently narrowed gastroesophageal junction, and a markedly delayed emptying of esophageal barium, all characteristic of achalasia. Endoscopic findings also supported this diagnosis. Esophageal motility studies demonstrated a high-normal LES pressure of $33 \mathrm{mmHg}$ (upper limit of normal for age is $40 \mathrm{mmHg}$ ). Additionally, there was no relaxation after swallowing and low-amplitude, simultaneous peristaltic contractions of the distal two-thirds of the esophageal body were recorded after both "wet" and "dry" swallows. After acute (intravenous for $40 \mathrm{~min}$ ) and long-term (oral for 30 days) treat- 
Table 1. Studies in family with $A C T H$ insensitivity

\begin{tabular}{|c|c|c|c|c|c|c|c|}
\hline & \multirow{2}{*}{$\begin{array}{l}\text { Age } \\
(\mathrm{yr})\end{array}$} & \multirow{2}{*}{$\begin{array}{c}\text { ACTH } \\
(\mathrm{pg} / \mathrm{ml})\end{array}$} & \multicolumn{2}{|c|}{$\begin{array}{l}\text { Cortisol } \\
(\mu \mathrm{g} / \mathrm{dl})\end{array}$} & \multicolumn{2}{|c|}{$\begin{array}{l}\text { Aldosterone } \\
\text { (ng/dl) }\end{array}$} & \multirow[b]{2}{*}{ HLA-type } \\
\hline & & & $0(\mathrm{~min})$ & $30^{1}(\mathrm{~min})$ & $0(\min )$ & $30^{1}(\mathrm{~min})$ & \\
\hline Father & 25 & 26 & 11 & $\mathrm{NT}^{3}$ & NT & NT & NT \\
\hline Mother & 22 & NT & 17.2 & 30.4 & 3.5 & 17.1 & $\mathrm{~A} 1, \mathrm{~A} 3, \mathrm{~B} 35, \mathrm{~B} 52$ \\
\hline Brother 1 & $2 / 12$ & 95 & 28.4 & 46.9 & $82.5^{2}$ & 130.4 & $\mathrm{~A} 1, \mathrm{~A} 31, \mathrm{~B} 49, \mathrm{~B} 52$ \\
\hline Brother 2 & $1 / 12$ & NT & 19.6 & 28.9 & $165.2^{2}$ & 177.2 & NT \\
\hline \multirow[t]{2}{*}{ Patient } & $26 / 12$ & $130-2000$ & \multicolumn{2}{|c|}{ Undetected } & 9.0 & 23.7 & A3, A19, B35, B49 \\
\hline & $36 / 12$ & 83 & \multicolumn{2}{|c|}{ Undetected } & 16.5 & 37.6 & NT \\
\hline
\end{tabular}

${ }^{2}$ Normal basal aldosterone values in the first year of life are higher than adult values (29).

${ }^{3} \mathrm{NT}$, not tested.

ment with theophylline, during which serum theophylline concentrations were between $10-20 \mu \mathrm{g} / \mathrm{ml}$, there was no significant improvement in esophageal motility. The patient's achalasia was subsequently treated by pneumatic dilatation with improvement in appetite and weight gain.

Ophthalmologic evaluation revealed central, steady, and maintained fixation in each eye. Pupils were each $3 \mathrm{~mm}$ and reactive to direct and consensual light; there was no afferent pupillary defect. He was orthophoric with full extraocular muscle motility. Slit-lamp examination using fluorescein demonstrated multiple punctate epithelial defects of the corneas, which were limited to the exposed regions. Cycloplegic refractive examination revealed moderate astigmatism $(+1.00+4.50 \times 100$ in the right eye; -1.50 $+4.00 \times 90$ in the left eye). On ophthalmoscopy, he had a normal optic nerve head and macula in each eye; retinal vasculature was normal. Although the patient was mildly sedated for esophagoscopy, further examination revealed normal-sized puncta of both upper and lower lids. The Schirmer test (without topical anesthesia) showed no $(0 \mathrm{~mm})$ tear production in either eye after $4 \mathrm{~min}$. Ocular lubrication, consisting of artificial tears and bland ointment, was prescribed.

Histamine injection resulted in intense pain and normal wheal and flare response (3).

In an attempt to examine the inheritance pattern of this condition, the patient's parents and younger male siblings underwent several studies. Testing was begun between 8:00-9:00 AM. The results, contrasted to those of the patient, are shown in Table 1. They indicate that, at the time of testing, the patient was the only member who appeared to be affected with glucocorticoid insufficiency and who demonstrated ACTH excess. The second male sibling was not HLA-identical to the patient and the third was not tested. Both younger siblings teared normally within the first few weeks of life.

\section{DISCUSSION}

A syndrome of glucocorticoid insufficiency has been described in several patients and families $(9,16,18-21,23,24,28,29,31,33$, 35,37 , with only two reports noting an association with achalasia and alacrima $(1,20)$. The studies of our patient document the association of complete unresponsiveness of the ZFZR to endogenous and exogenous ACTH with achalasia and alacrima. Defects in the endogenously produced ACTH molecule or the presence of a circulating antibody interfering with the assay of ACTH appear unlikely in view of the patient's failure to respond to exogenous ACTH and the normal slope of the plasma dilution curve of the ACTH RIA.

In published reports of patients with glucocorticoid deficiency or so-called ACTH insensitivity, there have been conflicting findings regarding the selectivity of the defect in ZFZR $(20,24,31)$. Although normal mineralocorticoid responsiveness to exogenous ACTH was suggested by the finding of increased urinary aldosterone excretion in at least one of two affected patients without achalasia and alacrima (24), a reduction in aldosterone secretion after ACTH infusion was reported in another similar patient with ACTH insensitivity (31). This discrepancy may have resulted from methodologic differences in testing because the latter patient was tested without suppression of endogenous ACTH, thereby potentially preventing sufficient access to the $\mathrm{ZG}$ receptors by exogenous ACTH. In addition, maintenance of the patient in a supine position before and during testing is essential in order to eliminate postural effects on mineralocorticoid secretion. Normalcy of the renin-angiotensin system was tested in our patient using furosemide diuresis preceding assumption of the upright posture (36). A brisk rise in the serum aldosterone concentration documented integrity of the ZG. Subsequently, at a time when the endogenous ACTH concentration was significantly suppressed and the patient maintained supine, we were able to demonstrate a normal aldosterone response to exogenous ACTH in the absence of any increase in serum concentrations of renin, or cortisol, thereby confirming the selectivity of the lesion.

In an attempt to distinguish complete atrophy of the ZFZR from a possible abnormality in the ACTH-dependent receptormediated steps of steroidogenesis, we reasoned that if the intracellular enzyme systems necessary for glucocorticoid synthesis were still functional, they might be stimulated by a compound such as theophylline. Acting through enhancement of the intracellular cyclic AMP concentration as a result of inhibition of phosphodiesterase-mediated hydrolysis (11), or by promoting other events such as calcium uptake (35), theophylline infusion did, indeed, result in detectable cortisol secretion when first administered to our patient; thus, the ZFZR could not have been completely atrophic at the time of initial testing. This is consistent with the findings reported in one affected family of initial responsiveness to ACTH followed by subsequent development of resistance (24). It also makes it unlikely that the underlying defect is a consequence of complete lack of fetal development and differentiation of these ACTH-dependent zones.

The few histologic specimens that are available from patients with ACTH sensitivity (all without known achalasia or alacrima) have shown atrophy of the ZFZR with preservation of normal $\mathrm{ZG}$ architecture $(21,36)$. When in vitro steroidogenesis was studied in one such specimen, an increased corticosterone to cortisol ratio, which was further increased by the addition of cyclic AMP, was found. The initial response to theophylline in our patient suggests that the primary defect in this disorder may be the inability of ACTH to bind its receptor in the ZFZR or to elicit a response in the cascade beyond the hormone-receptor interaction. The eventual failure of theophylline to stimulate steroidogenesis is consistent with the inevitable ZFZR atrophy that occurs after prolonged absence of ACTH stimulation regardless of the mechanism (25).

Defects in polypeptide-hormone binding to receptors or defects in immediate post-receptor steps involving the coupling mechanism necessary for cyclic-AMP generation have been implicated in other clinical or experimental conditions. These include the Type B form of acanthosis nigricans, familial hypercholesterole- 
mia, and pseudohypoparathyroidism (4). Specific enhancement of phosphodiesterase activity resulting in accelerated cyclic-AMP hydrolysis has been identified in the medullary tubules of mice with hereditary nephrogenic diabetes insipidus (17), an analogous disorder or end-organ unresponsiveness. Conversely, effectiveness of theophylline in stimulating cortisol production in our patient may have been non-specific and independent of the events leading to ultimate ZFZR atrophy. Preliminary studies of patients with other acquired forms of adrenal insufficiency suggest that theophylline-stimulated steroidogenesis may persist somewhat longer than ACTH dependence (10). Although the mechanism for such dissociation remains obscure, it appears that in some forms of adrenal insufficiency ZFZR failure occurs in a centripetal fashion, with loss of receptor recognition followed later by impairment of intracellular function.

Isolated ACTH insensitivity has been associated with two inheritance patterns autosomal recessive or X-linked $(9,36)$. Biochemical heterozygosity for the defect or HLA-linkage have not been delineated. In an attempt to elucidate whether either of these two might be present in our patient's family, HLA-typing, and Cortrosyn-stimulation tests were performed on the patient's mother and first brother. Only Cortrosyn-testing was performed on the second brother. The patient and his first brother were nonHLA-identical, sharing only one common locus. Cortrosyn-testing failed to reveal abnormalities in either cortisol or aldosterone responsiveness in either the patient's mother or his two siblings, and ACTH was not elevated in the mother. We were therefore unable to find evidence for heterozygosity in these family members.

The association of achalasia and alacrima with ACTH insensitivity has been previously described in two reports $(1,20)$ and adrenal insufficiency suspected in one of two siblings with achalasia (34). A unifying pathogenesis remains unknown. Pathologic studies in most patients with achalasia have shown degeneration and reduction in neuron counts in the vagal nuclei as well as in myenteric neurons in the LES and esophageal body (6). This may represent a primary defect or may be secondary to defects in synaptic or neuromuscular transmission due to defective transmitter synthesis, release, or metabolism (14). The nature of the transmitter is unknown and studies have suggested that, at least, adenosine and ATP are unlikely candidates (15). Alacrima, in children, is a rare ophthalmologic abnormality. It occurs as an isolated disorder inherited in an autosomal dominant pattern (22) or in association with familial dysautonomia (12); however, our patient's ethnic background, a normal response to intradermal histamine, and presence of fungiform papillae make the diagnosis of familial dysautonomia unlikely. Additionally, although esophageal dysmotility is seen in this disease, achalasia is not (3).

Although the achalasia and alacrima in this syndrome might be a consequence of parasympathetic denervation, a neurologic mechanism for the development of zone-specific resistance to ACTH is less evident. The adrenal medulla and, less prominently, the adrenal cortex (25) are innervated by two groups of autonomic fibers, one from the greater splanchnic nerve and upper lumbar sympathetic ganglia by way of the celiac plexus and ganglion, and the other from the vagus and phrenic nerves (32), thus, there appear to be both sympathetic and parasympathetic input to the adrenal gland. Although not directly involved in the response of the ZFZR to ACTH, the possibility that this innervation is important in the regulation of these zones cannot be excluded. Similarities to familial dysautonomia clearly exist, but our patient appears to have another rare syndrome characterized by ACTH insensitivity and a multifocal, yet highly localized, defect of the autonomic, or specifically the parasympathetic, nervous system, or its transmitter(s).

\section{REFERENCES AND NOTES}

1. Allgrove, H., Clayden, G. S., Grant, D. B., and McCaulay, J. C.: Familial glucocorticoid deficiency with achalasia of the cardia and deficient tear pro- duction. Lancet, $1: 1284$ (1978).

2. Ament, M. E. and Christie, C. L.: Upper gastrointestinal fiberoptic endoscopy in pediatric patients. Gastroenterology, 72: 1244 (1977).

3. Axelrod, F. B., Nachtigal, R., and Dancis, J.: Familial dysautonomia: diagnosis, pathogenesis and management. Adv. Pediatr., 21: 75 (1974).

4. Baxter, J. D., and Furder, J. W.: Hormone receptors. N. Engl. J. Med. 301: 1149 (1981).

5. Berson, S. A., and Yalow, R. S.: Radioimmunoassay of ACTH in plasma. J. Clin. Invest. 47: 2725 (1968).

6. Cassella, R. R., Brown, A. L., Sayre, G. P., and Ellis, F. H.: Achalasia of the esophagus: pathologic and etiologic considerations. Ann. Surg. 160:474 (1964).

7. Dluhy, R. G. Himathongkam, T., and Greenfield, M.: Rapid ACTH test with plasma aldosterone levels. Ann. Intern. Med., 80: 693 (1974).

8. Dodds, W. J.: Instrumentation of methods of intraluminal esophageal manometry. Arch. Intern. Med., 136: 515 (1976).

9. Franks, R. C. and Nance, W. E.: Hereditary adrenocortical unresponsiveness to ACTH. Pediatrics, 45: 43 (1970).

10. Geffner, M. E., Lippe, B. M., Kaplan, S. A., and Itami, R. M.: The use of theophylline as an in vivo probe of adrenocortical function. J. Clin. Endocrinol. Metab., 55: 56 (1982).

11. Gill, G. N.: ACTH regulation of the adrenal cortix. Pharmacol. Ther. B, 2: 323 (1976).

12. Goldberg, M. F., Payne, J. W., and Brunt, P. W.: Ophthalmic studies of familial dysautonomia. The Riley-Day Syndrome. Arch. Ophthalmol., 80: 732 (1968).

13. Gould, A. B., Skeggs, L. T., and Kahn, J. R.: Measurement of renin and substrate concentration in human serum. Lab. Invest., 15: 1802 (1966).

14. Goyal, R. K.: Pathophysiology of achalasia and diffuse esophageal spasm. The neuromuscular disorders of the gastrointestinal tract and selected updates in gastrointestinal diagnostic and therapeutic procedures. New York Hilton Hotel, New York, NY, May 16-17, 1981.

15. Goyal, R. K. and Cobb, B. W.: Motility of the pharynx, esophagus, and the esophageal sphincters. In Johnson, L. R., Ed.: Physiology of the Gastrointestinal Tract pp. 374-83. (Raven Press, New York, NY, 1981).

16. Imura, H.: Familial glucocorticoid deficiency, Nippon Rinsho, 37: 1233 (1979).

17. Jackson, B. A., Edwards, R. M. Valtin, H., and Dousa, T. P.: Celluiar action of vasopressin in medullary tubules of mice with hereditary nephrogenic diabetes insipidus. J. Clin. Invest., 66: 110 (1980).

18. Kelch, R. P., Kaplan, S. L., Biglieri, E., Daniels, G. H., Epstein, C. J., and Grumbach, M. M.: Hereditary adrenocortical unresponsiveness to adrenocorticotropic hormone. J. Pediatr., 81: 726 (1972)

19. Kershnar, A. K., Roe, T. F., and Kogut, M. D.: Adrenocorticotropic hormone unresponsiveness: report of a girl with excessive growth and review of 16 reported cases. J. Pediatr., 80: 610 (1972).

20. Lanes, R., Plotnick, L. P., Bynum, T. E., Lee, P. A., Casella, J. F., Fox, C. E. Kowarski, A. A., and Migeon, C. J.: Glucocorticoid and partial mineralocorticoid deficiency associated with achalasia. J. Clin. Endocrinol. Metab., 50: 268 (1980).

21. Migeon, C. J., Kenny, F. M., Kowarski, A., Snipes, C. A., Spaulding, J. S. Finkelstein, J. W., and Blizzard, R. M.: The syndrome of congenital adrenocortical unresponsiveness to ACTH., Report of six cases. Pediatr. Res., 2: 501 (1968).

22. Mondino, B. J. and Brown, S. I.: Hereditary congenital alacrima. Arch. Ophthalmol., 94: 1478 (1976).

23. Monteleone, J. A. and Monteleone, P. L.: Hereditary adrenocortical unresponsiveness to ACTH-another case. Pediatrics, 46: 321 (1970).

24. Moshang, T., Jr., Rosenfield, R. L., Bongiovanni, A. M., Parks, J. S., and Amshein, J. A.: Familial glucocorticoid insufficiency. J. Pediatr., 82: 821 (1973).

25. Nelson, D. H.: The adrenal cortex: physiological function and disease. In Smith, Jr., L. H. Ed., Major Problems in Internal Medicine, XVIII, p. 4 (W. B. Saunders Company, Philadelphia, PA, 1980).

26. Nerup, J.: Addison's disease-serological studies. Acta Endocrinologica, 76: 142 (1974).

27. Piafsky, K. M. and Ogilvie, R. L.: Dosage of theophylline in bronchial asthma. N. Engl. J. Med., 292: 1218 (1975).

28. Preeyasombat, C., Viriyapanich, P., Sriboonsuang, S., and Pitchayayothin, N.: Hereditary primary glucocorticoid insufficiency. J. Med. Assoc. Thailand, 59. 168 (1976).

29. Shepard, T. H., Landing, B. H., and Mason, D. G.: Familial Addison's disease. Amer. J. Dis. Child., 97: 154 (1959).

30. Siegler, R. L., Crouch, R. H., Hackett, Jr., T. N., Walker, M., and Jubiz, W.: Potassium-renin-aldosterone relationships during the first year of life. J. Pediatr., 91: 52 (1977).

31. Spark, R. F. and Etzkorn, J. R.: Absent aldosterone response to ACTH in familia glucocorticoid deficiency. N. Engl. J. Med., 47: 917 (1977).

32. Symington, T.: Functional Pathology of the Human Adrenal Gland. p. 20 (E. \& S. Livingstone Ltd., Edinburgh, 1969)

33. Thistlewaite, D., Darling, J. A. B., Fraser, R., Mason, P. A., Rees, L. H., and Harkness, R. A.: Familial glucocorticoid deficiency. Arch. Dis. Child. 50: 291 (1975).

34. Vaughn, W. H. and Williams, J. L.: Familial achalasia with pulmonary complications in children. Radiology, 107: 407 (1973).

35. Wells, J. N. and Kramer, G. L.: Phosphodiesterase inhibitors as tools in cyclic nucleotide research: a precautionary comment. Molec. and Cell Endocrinol., 23: 1 (1981)

36. Werder, E. A., Haller, R., Vetter, W., Zachmann, M., and Siebermann, R.: 
Isolated glucocorticoid deficiency, Helv. Paediat. Acta, 30: 175 (1975).

37. Williams, H. E., and Freeman, M.: Primary familial Addison's disease. Austral. Paediatr. J., 1: 93 (1965).

38. Presented in part before the Joint Meetings of the Western Section American Federation for Clinical Research, Western Society for Pediatric Research, and Western Region, The Society for Investigative Dermatology, Carmel, CA, February 6, 1981, and at the Annual Meetings of the Society for Pediatric
Research, San Francisco, CA, April 28, 1982. Published in part as abstracts in Clin. Res., 29: 109 (1981) and Pediatr. Res., 15: 507 (1981).

39. Requests for reprints should be addressed to: Dr. Mitchell E. Geffner, UCLA School of Medicine, MDCC 22-315, Los Angeles, CA 90024

40. Supported by USPHS Grant \#RR-865, National Institutes of Health.

41. Received for publication April 27, 1982

42. Accepted for publication September 24, 1982.

Copyright $(\subset) 1983$ International Pediatric Research Foundation, Inc.

0031-3998/83/1707-0532\$02.00/0

Printed in U.S.A. 